\title{
Activation of the Class Ib Ribonucleotide Reductase by a Flavodoxin Reductase in Bacillus cereus
}

\author{
Marie Lofstad, ${ }^{\ddagger}$, Ingvild Gudim, $^{\ddagger},{ }^{\text {Marta Hammerstad, }}{ }^{\S}$ Åsmund Kjendseth Røhr, ${ }^{\dagger}$ Hans-Petter Hersleth ${ }^{\S, *}$ \\ ${ }^{\S}$ Department of Biosciences, Section for Biochemistry and Molecular Biology, University of Oslo, P.O. Box 1066 Blindern, \\ NO-0316 Oslo, Norway \\ ${ }^{+}$Department of Chemistry, Biotechnology and Food Science, Norwegian University of Life Sciences, P.O. Box 5003, NO-1432 Ås, \\ Norway \\ † These authors contributed equally
}

\section{TABLE OF CONTENTS}

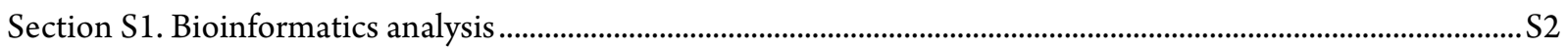

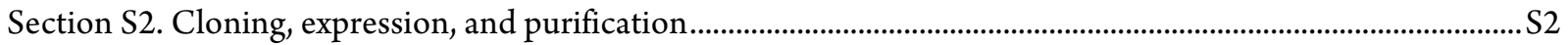

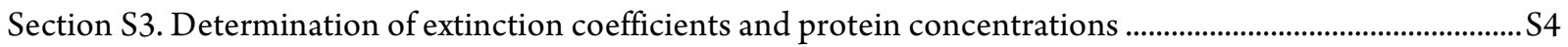

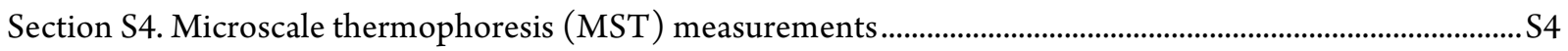

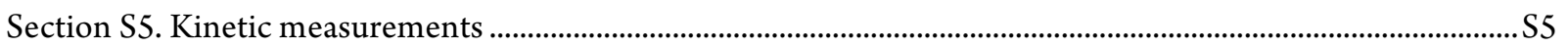

Section S6. NrdF activation and electron paramagnetic resonance (EPR) measurements..................................S6

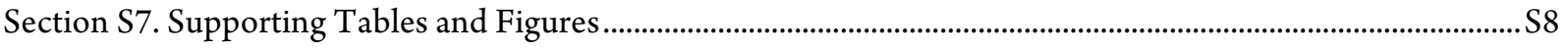

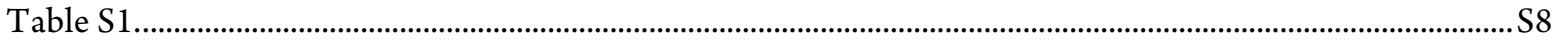

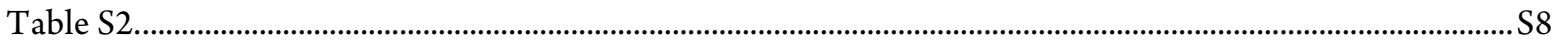

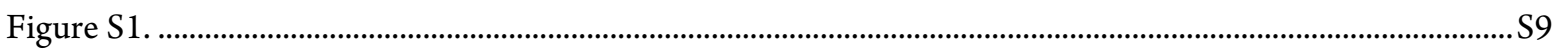

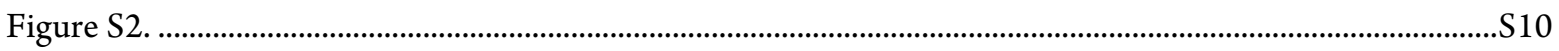

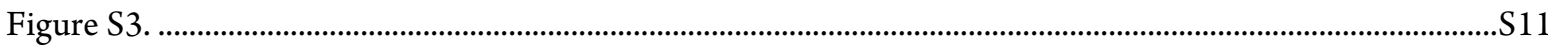

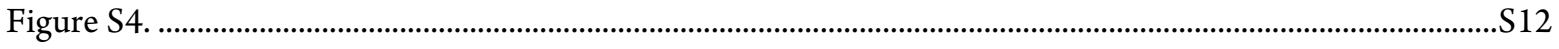

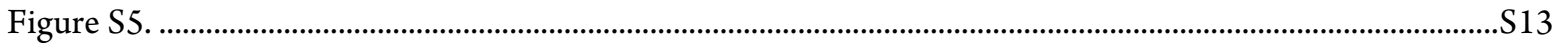

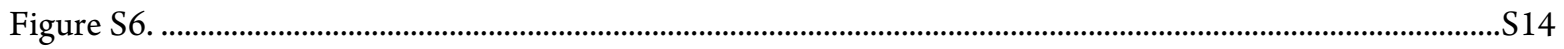

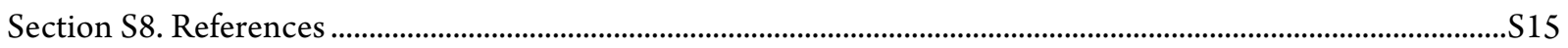




\section{Section S1. Bioinformatics analysis}

Flavodoxin-ferredoxin $\mathrm{NADP}^{+}$oxidoreductases (FNRs) are probable reduction partners for the flavodoxin-like protein NrdI, involved in the redox pathway of class Ib ribonucleotide reductase (RNR). Therefore, the Bacillus cereus (ATCC 14579) genome was searched for annotated FNRs. B. cereus does not contain any genes with homology to the FNR type found in Escherichia coli; however, it contains three genes that have been annotated as FNRs/thioredoxin reductases (TrxRs) (BC0385, BC4926, BC1495). These genes lack the catalytic CXXC motif of TrxRs, ${ }^{1}$ and most likely encode FNRs. Sequence alignments show that the identified FNRs and TrxR in B. cereus share a sequence identity of $25-29 \%$ (Table S1), and the FNRs thus belong to the so-called TrxR-like FNRs found in many bacteria, especially Firmicutes. ${ }^{2}$ In some annotations BC0385 and BC4926 have been called FNR1 and FNR2, respectively, and these names will be used henceforth. Likewise, BC1495 will be called FNR3.

The genomic search for FNRs revealed that Bacillus anthracis (strain Sterne), which is closely related to B. cereus, also contains three similar FNRs. Furthermore, the widely studied Bacillus subtilis (subsp. subtilis str. 168) encodes three possible TrxR-like FNRs - YumC, YcgT, and YpdA - with YumC sharing 78\% sequence identity with FNR2 in B. cereus (Table S1). In contrast, E. coli (K-12 substr. MG1655) does not contain any TrxR-like FNR homologs, except for its own TrxR. B. cereus, B. anthracis and B. subtilis all belong to the Firmicutes phylum of bacteria and they contain genes encoding class Ib RNR. Two other bacterial species from which class Ib RNR has been studied, Lactococcus lactis (MG1363) and Streptococcus sanguinis (SK36), each encodes one TrxR-like FNR, respectively: TrxB2 and TrxR2. The L. lactis FNR and S. sanguinis FNR are most homologous to FNR2 in B. cereus, with which they share 41 and $54 \%$ sequence identity, respectively (Table S2). Recent studies of the FNR in L. lactis indicate that this protein is essential for aerobic growth of these bacteria, and that it can be a redox partner for NrdI. ${ }^{3}$ The FNR in S. sanguinis has been tested out as a TrxR in class Ib RNR without success; ${ }^{4}$ however, it lacks the catalytic CXXC motif characteristic of TrxRs. Nonetheless, it contains a rare CCx[C/S/G] motif, which has only been found in some plant glutaredoxins. ${ }^{5}$ These observations suggest that also the S. sanguinis FNR could be a possible NrdI reductase. Multiple sequence alignments with Clustal Omega ${ }^{6}$ in Jalview $^{7}$ and phylogenetic tree analysis with BLOSUM62 in Jalview demonstrated a clustering of the discussed genes into three clouds (Figure S1 and S2): the TrxR cloud (blue), the FNR1/FNR2 cloud (olive/orange) and the FNR3 cloud (red). Moreover, FNR3 was found to be the least related to the other FNR and TrxR proteins.

\section{Section S2. Cloning, expression, and purification}

\section{FNR3 (BC1495)}

pET-22b(+) plasmid containing the gene BC1495 (B. cereus ATCC 14579, GenScript) and restriction sites NdeI-BamHI without any tags was transformed into competent BL21 (DE3) cells (Novagen). Cells were grown from freeze stocks on Luria-Bertani (LB) agar plates with $100 \mu \mathrm{g} \mathrm{mL} \mathrm{m}^{-1}$ ampicillin (Sigma). A single colony was inoculated into $5 \mathrm{~mL} \mathrm{LB}$ media ( $100 \mu \mathrm{g} \mathrm{mL}{ }^{-1}$ ampicillin in all growths) and grown overnight at $37^{\circ} \mathrm{C}$ with vigorous shaking. The overnight culture was diluted 50x into $100 \mathrm{~mL} \mathrm{LB}$ media and after 6 hours diluted 100x into $1 \mathrm{~L}$ Terrific Broth (TB) media. When the cells had grown to an OD at $600 \mathrm{~nm}$ of $0.8-1$, the cultures were cooled on ice until they reached $20{ }^{\circ} \mathrm{C}$, and subsequently induced by adding isopropyl $\beta$-D-1thiogalactopyranoside (IPTG, Thermo Scientific) to a final concentration of $1 \mathrm{mM}$. Cultures were grown for 1215 hours at $20^{\circ} \mathrm{C}$ before the cells were harvested by centrifugation $(\sim 6400 \mathrm{~g}, 12 \mathrm{~min})$. The cell paste was stored at $-20^{\circ} \mathrm{C}$.

Approximately $30 \mathrm{~g}$ of cell paste was lysed using an X-press system ${ }^{8}$ and the lysate was dissolved in $100 \mathrm{~mL}$ buffer (100 mM Tris-HCl pH 7.5, 2 mM DTT, 1 mM EDTA) supplemented by 1 tablet cOmplete Protease Inhibitor 
Cocktail Tablet Mini (Roche), before cell debris was removed by centrifugation ( $48000 g, 60 \mathrm{~min})$. DNA was precipitated by adding streptomycin sulfate to a final concentration of $2.5 \%(\mathrm{w} / \mathrm{v})$ and discarded after centrifugation at $48000 \mathrm{~g}$ for $30 \mathrm{~min}$. Finally, solid ammonium sulfate $\left(0.25 \mathrm{~g} \mathrm{~mL}^{-1}\right)$ was added to the supernatant to precipitate contaminant proteins, and the precipitate was removed by centrifugation $(\sim 15000 \mathrm{~g}, 45 \mathrm{~min})$. More ammonium sulfate was added to the supernatant to a final concentration of $0.35 \mathrm{~g} \mathrm{~mL}^{-1}$ and, after centrifugation $(\sim 15000 \mathrm{~g}, 45 \mathrm{~min})$, the precipitated protein was further purified. SDS-PAGE was used to confirm at which ammonium sulfate concentration the overexpressed protein precipitated.

The protein was dissolved in purification buffer ( $50 \mathrm{mM}$ Tris- $\mathrm{HCl} \mathrm{pH}$ 7.5, $1 \mathrm{mM}$ EDTA, $2 \mathrm{mM} \mathrm{DTT}$ ), and desalted on $2 \times 5 \mathrm{~mL}$ HiTrap Desalting columns (GE Healthcare) using an ÄKTA purifier FPLC system (GE Healthcare). The desalted protein was applied on an XK26 column containing $70 \mathrm{~mL}$ HP Q anion-exchange material (GE Healthcare), and eluted using a stepwise gradient of $150-500 \mathrm{mM} \mathrm{KCl}$ in the purification buffer over 17 column volumes. The FNR-containing fractions were pooled and concentrated in a Centricon Plus-70 filter unit (30 kDa MWCO, Millipore). As a final purification step, size exclusion chromatography was used. An XK16 column containing $120 \mathrm{ml}$ Superdex 200 material (GE Healthcare) was equilibrated with $25 \mathrm{mM}$ HEPES pH 7.5, $100 \mathrm{mM} \mathrm{KCl}$ and $2 \mathrm{mM} \mathrm{DTT}$, and the protein was eluted with the same buffer. The FNR-containing fractions were pooled and concentrated in an Amicon Ultra-15 filter unit (30 kDa MWCO, Millipore). The protein concentration was measured using a UV-vis spectrophotometer (see section S3) and samples were aliquoted, flash-frozen in liquid $\mathrm{N}_{2}$, and stored at $-80^{\circ} \mathrm{C}$.

\section{FNR2 (BC4926)}

The BC4926 (B. cereus ATCC 14579) gene was amplified by PCR using genomic DNA of B. cereus and the genespecific forward (5'-CCCTCTAGAAATAATTTTGTTTAACTTTAAGAAGGAGATATACATATGAAA GTGGCAGAAAATCAA - 3') and reverse primers (5' - GCCGGATCC TTAAAACATGCTTGAGCTATGC - 3'). The FNR2 PCR product and pET-22b(+) expression vector (Novagen) were separately double-digested with FastDigest XbaI and BamHI restriction enzymes (Fermentas) and mixed for ligation. The ligation product was first transformed into E. coli XL10-Gold Ultra-competent cells (Stratagene) and in a second step into E. coli BL21(DE3) Competent cells (New England BioLabs); the latter were used for protein expression. The resulting pET-22b-FNR2 plasmid does not contain the pelB leader sequence owing to the use of the XbaI and BamHI restriction enzymes, and FNR2 is expressed without any tags.

FNR2 was expressed and lysed following the same protocol as for FNR3, with minor modifications. All buffers were adjusted to $\mathrm{pH} 8.0$, and the protein was precipitated with $0.2 \mathrm{~g} \mathrm{~mL}^{-1}$ ammonium sulfate, without any preceding steps removing contaminant proteins.

The protein was dissolved in purification buffer (50 mM Tris- $\mathrm{HCl} \mathrm{pH} \mathrm{8.0,2} \mathrm{mM} \mathrm{DTT}$ ) and desalted on an XK26 column containing $70 \mathrm{~mL}$ Sephadex G-25 Fine material (GE Healthcare). Desalted protein was applied on an XK26 column containing $70 \mathrm{~mL} H \mathrm{H}$ Q anion-exchange material (GE Healthcare), and eluted using a stepwise gradient of $0-300 \mathrm{mM} \mathrm{KCl}$ in the purification buffer over 20 column volumes. The FNR-containing fractions were pooled and concentrated in a Centricon Plus-70 filter unit (30 kDa MWCO, Millipore). In order to separate the unstable monomer from the stable dimer, another ion-exchange chromatography step was carried out, using an XK16 column packed with $50 \mathrm{~mL}$ Source 15Q material, equilibrated with $50 \mathrm{mM}$ HEPES pH 8.0 and $2 \mathrm{mM}$ DTT. The protein was eluted using a linear gradient of $100-200 \mathrm{mM} \mathrm{KCl}$ in the same buffer over 15 column volumes. Fractions containing dimeric FNR were pooled and concentrated (Centricon Plus-70 filter unit, $30 \mathrm{kDa}$ MWCO, Millipore). Finally, size-exclusion chromatography was used as a last polishing step. An XK16 column containing $120 \mathrm{ml}$ Superdex 200 material (GE Healthcare) was equilibrated with $50 \mathrm{mM}$ HEPES pH 8.0, 
$100 \mathrm{mM} \mathrm{KCl}$ and $2 \mathrm{mM} \mathrm{DTT}$, and the protein was eluted with the same buffer. FNR-containing fractions were pooled and concentrated in an Amicon Ultra-15 filter unit ( $30 \mathrm{kDa}$ MWCO, Millipore). The protein concentration was measured as described in section S3 and samples were aliquoted, flash-frozen in liquid $\mathrm{N}_{2}$, and stored at $-80^{\circ} \mathrm{C}$.

\section{FNR1 (BC0385)}

FNR1 was expressed and purified without any tags as previously described, ${ }^{9}$ with minor deviations. Contaminant proteins were precipitated using $0.3 \mathrm{~g} \mathrm{~mL}^{-1}$ ammonium sulfate. To the supernatant, more ammonium sulfate was added to a final concentration of $0.4 \mathrm{~g} \mathrm{~mL}^{-1}$, and FNR1 protein was precipitated. This was confirmed by SDSPAGE.

\section{Nrdl and NrdF}

B. cereus (ATCC 14579) NrdI (BC1353) and NrdF (BC1355) proteins were expressed and purified as previously described; ${ }^{10,11}$ with a slightly modified NrdF purification protocol. An additional ammonium sulfate precipitation $\left(0.2 \mathrm{~g} \mathrm{ml}^{-1}\right)$ and centrifugation step was introduced to remove contaminant proteins, and NrdF was precipitated from the supernatant with $0.35 \mathrm{~g} \mathrm{ml}^{-1}$. The NrdF-containing fractions from size-exclusion chromatography were pooled, concentrated, and applied to an XK16 column packed with $50 \mathrm{~mL}$ Source 15Q anion exchange material, and highly purified protein (>95\%) was eluted with a $200-450 \mathrm{mM} \mathrm{KCl}$ gradient (in $50 \mathrm{mM}$ HEPES, pH 7.5). Purified NrdF generally contained less than $10 \%$ iron, as determined by inductively coupled plasma optical emission spectroscopy (Stanford University, Environmental Measurements Facility).

\section{Section S3. Determination of extinction coefficients and protein concentrations}

Protein concentrations were determined using an Agilent $8453 \mathrm{UV}$-visible spectrophotometer. Concentrations of NrdI and NrdF samples were assessed from the absorbance at 450 or $280 \mathrm{~nm}$, respectively, using $\mathcal{E}_{450 \mathrm{ox}}=10.8 \mathrm{mM}^{-1} \mathrm{~cm}^{-112}$ or $\varepsilon_{280}=47.7 \mathrm{mM}^{-1} \mathrm{~cm}^{-1}$ (NrdF monomer, as determined with the Edelhoch method). ${ }^{13}$

The extinction coefficients of all three FNRs were determined by SDS treatment, using $\varepsilon_{450 \mathrm{ox}}=11.3 \mathrm{mM}^{-1} \mathrm{~cm}^{-1}$ for free FAD, as described by Vanoni and coworkers. ${ }^{14}$ Extinction coefficients of the oxidized proteins at their corresponding $\lambda_{\max }$ were found to be $\varepsilon_{462 \mathrm{ox}}=9.9 \mathrm{mM}^{-1} \mathrm{~cm}^{-1}$ for FNR1, $\varepsilon_{4530 \mathrm{x}}=11.5 \mathrm{mM}^{-1} \mathrm{~cm}^{-1}$ for FNR3, and $\varepsilon_{4690 \mathrm{ox}}=11.1 \mathrm{mM}^{-1} \mathrm{~cm}^{-1}$ for FNR2. These values were used to determine the protein concentrations in all experiments.

\section{Section S4. Microscale thermophoresis (MST) measurements}

NrdI was labeled with the amine-reactive NT-647 dye (Nanotemper Technologies), according to the manufacturer's instructions. The labeling reaction and all binding assays were carried out in the same buffer (50 mM HEPES $\mathrm{pH} 7.5,100 \mathrm{mM} \mathrm{KCl}$ ). The assay buffer contained, in addition, Tween-20 to a final concentration of $0.05 \%$. A 1:1 serial dilution of unlabeled FNR in assay buffer was prepared and an equal volume of labeled NrdI at a low, fixed concentration was added to all samples. The samples were left to incubate for $5 \mathrm{~min}$ before they were loaded into standard treated capillaries (Nanotemper Technologies). Data collection was carried out at $25{ }^{\circ} \mathrm{C}$ in a Monolith NT.115 apparatus equipped with a blue/red filter (Nanotemper Technologies). Data was recorded at $20 \%$ LED power, and 20 and $40 \%$ MST power. Data analysis was carried out using MO.Affinity Analysis (Nanotemper Technologies) and Origin softwares (OriginLab Corporation), using the data recorded at 
$20 \%$ excitation power and $40 \%$ MST power. The $K_{\mathrm{D}}$ s were determined in MO.Affinity Analysis. The data was fitted with the $K_{\mathrm{D}}$ model option, and thermophoresis with $\mathrm{T}$ jump was chosen as the MST evaluation strategy.

\section{Section S5. Kinetic measurements}

Due to Nrdl's high reactivity with dioxygen, all experiments (unless otherwise stated) were carried out in a glove box (Plas Labs 855-AC) under strict anaerobic conditions $\left(91 \% \mathrm{~N}_{2}, 9 \% \mathrm{H}_{2}, \mathrm{AGA}\right)$. All solutions were degassed on a Schlenk line before transfer to the glove box. Buffers and stock solutions were sparged with pure argon for $2 \mathrm{~h}$ in a vented container, while proteins were subjected to 3 or 4 cycles of evacuation ( $5 \mathrm{~min}$ ) and refilling with argon (10 $\mathrm{min})$.

All reactions were performed at $30{ }^{\circ} \mathrm{C}$ in $50 \mathrm{mM}$ HEPES pH 7.5 and $50 \mathrm{mM} \mathrm{KCl}$ with constant stirring, unless otherwise stated. The kinetic experiments were monitored using an Agilent $8453 \mathrm{UV}$-visible spectrophotometer, and the temperature in the UV-vis cell was controlled with a temperature control accessory (Agilent 89090A).

\section{Cytochrome c reduction by FNRs}

The ability of the three FNRs to reduce cytochrome $c$ was monitored in a reaction containing $200 \mu \mathrm{M} \mathrm{NADPH}$ (AppliChem), $10 \mu \mathrm{M}$ cytochrome $c$ (equine heart, Sigma) and $0.5 \mu \mathrm{M}$ FNR. FNR and NADPH were mixed together in a quartz cuvette, and incubated and stirred for $15 \mathrm{~min}$, before cytochrome $c$ was added to start the reaction. A UV-vis spectrum was measured every $2 \mathrm{~s}$ for $15 \mathrm{~min}$, and the absorbance increase at $550 \mathrm{~nm}$ was monitored $\left(\Delta \varepsilon_{550}=21.1 \mathrm{mM}^{-1} \mathrm{~cm}^{-1}\right.$, with $\left.\varepsilon_{5500 x}=8.4 \mathrm{mM}^{-1} \mathrm{~cm}^{-1}, \varepsilon_{550 \mathrm{red}}=29.5 \mathrm{mM}^{-1} \mathrm{~cm}^{-1}\right)$. In Figure S3 the generation of reduced cytochrome $c$ is shown as a function of time after mixing with FNR and NADPH.

\section{Initial reduction studies of Nrdl by FNRs}

NrdI reduction by FNRs was studied spectrophotometrically, and the three main oxidation states of NrdI were followed - oxidized (ox), semiquinone (sq), and hydroquinone (hq). Reactions containing $200 \mu \mathrm{M} \mathrm{NADPH}$, $10 \mu \mathrm{M} \mathrm{NrdI}$ and $0.5 \mu \mathrm{M}$ FNR were monitored for 15-25 min, with a spectrum collected every $2 \mathrm{~s}$. The reduction of $\mathrm{NrdI}$ was monitored by the disappearance of the $\mathrm{NrdI}_{\text {ox }}$ state with $\lambda_{\max }=447 \mathrm{~nm}$ and appearance of the $\mathrm{NrdI}_{\mathrm{sq}}$ state with $\lambda_{\max }=575 \mathrm{~nm}$, additionally NADPH consumption was followed by the absorbance decrease at $340 \mathrm{~nm}$.

In Figure S3 the amount of $\mathrm{NrdI}_{\mathrm{ox}}$ and $\mathrm{NrdI}_{\mathrm{sq}}$ is shown as a function of time after mixing with FNR and NADPH for each of the three FNRs. The amount of $\mathrm{NrdI}_{\mathrm{sq}}$ was calculated from the absorbance at $575 \mathrm{~nm}$. The amount of $\mathrm{NrdI}_{\mathrm{ox}}$ was calculated from the absorbance at $447 \mathrm{~nm}$, minus the estimated contribution from $\mathrm{NrdI}_{\mathrm{sq}}$ at $447 \mathrm{~nm}$, and normalized (using the following estimates: $\varepsilon_{574 \mathrm{sq}} \approx 4.5, \varepsilon_{447 \mathrm{sq}} \approx 4.2, \varepsilon_{447 \mathrm{ox}} \approx 10.8 \mathrm{mM}^{-1} \mathrm{~cm}^{-1}$, which are based upon $\varepsilon_{580 \mathrm{sq}}=4.5$ and $\varepsilon_{450 \mathrm{ox}}=10.8 \mathrm{mM}^{-1} \mathrm{~cm}^{-1} 12$ and the $\mathrm{UV}$-vis spectra of $\mathrm{NrdI}_{\mathrm{ox}}$ and $\left.\mathrm{NrdI}_{\mathrm{sq}}\right)$.

Performing the same experiment as described above without adding FNR resulted in no changes in the UV-vis spectrum of NrdI, demonstrating that NADPH is not able to reduce NrdI.

\section{Steady-state kinetics of $\mathrm{Nrdl}$ reduction by FNRs}

Steady-state kinetic parameters for the three FNRs and NrdI were measured. Reduction of NrdI was monitored by the disappearance of the $\mathrm{NrdI}_{\mathrm{ox}}$ state with $\lambda_{\max }=447 \mathrm{~nm}$ and appearance of the $\mathrm{NrdI}_{\mathrm{sq}}$ state with $\lambda_{\max }=575 \mathrm{~nm}$. All reactions were carried out with $200 \mu \mathrm{M}$ NADPH, $0.5 \mu \mathrm{M}$ FNR, and various concentrations of NrdI (1$100 \mu \mathrm{M})$. NADPH and FNR were incubated and stirred for $15 \mathrm{~min}$, and NrdI was added to start the reaction. The initial reduction rate in $\mu \mathrm{M} \mathrm{min}^{-1}$ was determined by plotting the reduction of $\mathrm{NrdI}$ as a function of time, and estimating the initial slope. The amount of reduced NrdI was calculated from the absorbance at $447 \mathrm{~nm}$ minus the estimated contribution from $\mathrm{NrdI}_{\mathrm{sq}}$ at $447 \mathrm{~nm}$, as described above. 
The initial reduction rates $\left(v_{\mathrm{i}}\right)$ were plotted against NrdI concentration, and the data plots for each FNR was fitted with the Michaelis-Menten function $v_{i}=\frac{V_{\max } \cdot[\mathrm{NrdI}]}{K_{\mathrm{M}}+[\mathrm{NrdI}]}$ using Origin (OriginLab Corperation). The Michaelis-Menten graphs are presented in Figure 2, whereas $k_{\mathrm{cat}}, K_{\mathrm{M}}$, and other kinetic parameters are reported in Table 1.

\section{Section S6. NrdF activation and electron paramagnetic resonance (EPR) measurements}

\section{Activation of Nrdl and NrdF with FNRs under pre-anaerobic conditions}

A cuvette containing $80 \mu \mathrm{M}$ NrdI and $0.5 \mu \mathrm{M}$ FNR2 was prepared inside the glove box. NADPH ( $3 \mathrm{mM}$ ) was added in $10 \mu \mathrm{l}$ aliquots and the reaction was monitored with an Agilent $8453 \mathrm{UV}$-vis spectrophotometer, until NrdI reached the sq or hq state. This required an addition of 30 or $60 \mu \mathrm{lNADPH}$, respectively.

Degassed NrdF was reconstituted with 5 eq of freshly prepared $\mathrm{Mn}^{\mathrm{II}}\left(\mathrm{MnCl}_{2} \cdot 4 \mathrm{H}_{2} \mathrm{O}\right.$, Merck) per protein dimer $\left(\beta_{2}\right)$, and incubated at $30^{\circ} \mathrm{C}$ for $45-60 \mathrm{~min}$, while $\mathrm{NrdI}_{\mathrm{sq}}$ or $\mathrm{NrdI}_{\mathrm{hq}}$ was prepared (see description above). Reduced NrdI was mixed with $\mathrm{Mn}^{\mathrm{II}}-\mathrm{NrdF}$ in a 1:1 ratio (1 NrdI per NrdF monomer), and incubated for $5 \mathrm{~min}$. No change in the oxidation state of $\mathrm{NrdI}$ was observed during the incubation time. After incubation, the sample containing $\mathrm{Mn}^{\mathrm{II}}$-NrdF-NrdI $\mathrm{Nq}_{\mathrm{sq}}$ hq was removed from the glove box and mixed with aerobic buffer, pre-flushed with $\mathrm{O}_{2}$ (AGA). The samples were desalted on $2 \times 5 \mathrm{~mL}$ HiTrap Desalting columns (GE Healthcare) using an ÄKTA purifier FPLC system (GE Healthcare), in order to remove unbound $\mathrm{Mn}^{\mathrm{II}}$. Then, desalted protein samples were concentrated to $200 \mu \mathrm{l}$, transferred to an EPR tube, and flash-frozen in liquid nitrogen. The EPR samples, containing $\sim 400 \mu \mathrm{M}$ $\mathrm{NrdF}$ monomer, were stored in liquid nitrogen for a maximum of two weeks, before tyrosyl radical $(\mathrm{Y} \bullet)$ was quantified by EPR spectroscopy at $77 \mathrm{~K}$ (see description below). EPR spectra of activated NrdF protein are shown in Figure S4, and the estimated amount of $\mathrm{Y} \bullet / \beta_{2}$ is given in Table 2.

\section{Aerobic activation of Nrdl and NrdF with FNRs}

$\mathrm{NrdF}$ was incubated with 3.5-4.0 $\mathrm{Mn}^{\mathrm{II}} / \beta_{2}$ at room temperature for at least $30 \mathrm{~min}$ before activation. The reaction mixture containing FNR2 or FNR1, NrdI and $\mathrm{Mn}^{\mathrm{II}}$-reconstituted NrdF was incubated for 5 min in a quartz cuvette at $25^{\circ} \mathrm{C}$, and an excess of NADPH was added to start the reaction, which was performed with constant stirring. The oxidation state of $\mathrm{NrdI}$ and $\mathrm{Y} \bullet$ formation were monitored spectrophotometrically using an Agilent $8453 \mathrm{UV}$-visible spectrophotometer for $10 \mathrm{~min}$ at $450-620 \mathrm{~nm}$ and $409 \mathrm{~nm}$, respectively, as shown for FNR2 in Figure S5. The reaction mixture was concentrated to $\sim 200 \mu \mathrm{l}$, transferred to an EPR tube, and flash-frozen in liquid nitrogen after a total time of $\sim 23 \mathrm{~min}(0.4 \mathrm{~h})$ since the reaction was initiated. The final protein concentrations of the EPR samples were $\sim 150 \mu \mathrm{M}$ NrdF monomer, $\sim 150 \mu \mathrm{M}$ NrdI, $15 \mu \mathrm{M}$ FNR, and $2.5 \mathrm{mM}$ $\mathrm{NADPH}$. The concentration of $\mathrm{Y} \bullet$ in the EPR samples was determined by EPR spectroscopy at $77 \mathrm{~K}$ (see description below). Similar experiments were carried out with lower amounts of $\operatorname{NrdI}(15 \mu \mathrm{M})$ and were allowed to run until NADPH was fully consumed $(\sim 1.5 \mathrm{~h})$. Additionally, control experiments without NADPH, NrdF and $\mathrm{Mn}^{\mathrm{II}}$, or $\mathrm{Mn}^{\mathrm{II}}$ were performed. EPR samples were made from these experiments as described above, and $\mathrm{Y} \bullet$ concentration was determined by EPR spectroscopy at $77 \mathrm{~K}$ (see description below).

All EPR spectra collected at $77 \mathrm{~K}$ from aerobic activation of $\mathrm{NrdF}$ are given in Figure 3, and the estimated amount of $\mathrm{Y} \bullet / \beta_{2}$ from each experiment is given in Table 2 . The control without $\mathrm{Mn}^{\mathrm{II}}$ contained only $0.03 \mathrm{Y} \bullet / \beta_{2}$. Furthermore, EPR spectra of NrdF activated by FNR2 and NrdI at different temperatures (3.8-100 K) are shown in Figure S6. 


\section{$X$-band EPR spectroscopy}

X-band EPR spectra were recorded using a Bruker Elexsys 560 EPR spectrometer (Bruker Biospin) equipped with a quartz finger dewar for measurements at $77 \mathrm{~K}$ or an Oxford ESR 900 helium flow cryostat for measurements at 3.8-100 K. For measurements with liquid helium a Super X kv319 cavity was used.

Spin quantitation was carried out by double integration of the $\mathrm{Y} \bullet$ signal and comparison with a copper perchlorate standard containing $0.2 \mathrm{mM} \mathrm{Cu}^{2+}$ (made from $\mathrm{CuCl}_{2} \cdot 2 \mathrm{H}_{2} \mathrm{O}$, Sigma-Aldrich) and $1 \mathrm{M} \mathrm{HClO}_{4}$ (Merck) at nonsaturating conditions. 


\section{Section S7. Supporting Tables and Figures}

Table S1. Percentage of sequence identity between TrxRs and FNRs in B. cereus (bc) and B. subtilis (bs). The pairwise sequence alignment was generated with the BLOSUM62 scoring matrix in Jalview.

\begin{tabular}{|c|c|c|c|c|c|c|c|c|}
\hline & $b c$ FNR2 & $b c$ FNR 1 & $b c$ FNR3 & $b c \operatorname{TrxR}$ & bsYumC & $b s Y c g T$ & $b s Y p d A$ & bsTrxR \\
\hline bcFNR2 & & 41 & 23 & 29 & 78 & 46 & 23 & 30 \\
\hline bcFNR1 & & & 22 & 25 & 39 & 42 & 24 & 25 \\
\hline$b c$ FNR3 & $\theta$ & & & 26 & 22 & 24 & 75 & 28 \\
\hline$b c \operatorname{TrxR}$ & & & & & 27 & 27 & 24 & 85 \\
\hline bsYumC & & & & & & 48 & 24 & 28 \\
\hline$\overline{b s Y c g T}$ & & & & & OS & D & 26 & 26 \\
\hline$b s Y p d A$ & & & & & & & 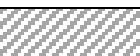 & 25 \\
\hline bsTrxR & & & & & & & 18 & III \\
\hline
\end{tabular}

Table S2. Percentage of sequence identity between FNRs in B. cereus (bc), B. anthracis (ba), B. subtilis (bs), L. lactis (ll), and S. sanguinis (ss). The pairwise sequence alignment was generated with the BLOSUM62 scoring matrix in Jalview.

\begin{tabular}{|c|c|c|c|c|c|c|c|c|}
\hline & $b c$ FNR2 & bsYumC & baFNR2 & ssFNR & //FNR & $b c F N R 1$ & bsYcgT & baFNR1 \\
\hline$b c$ FNR2 & DII & 78 & 99 & 54 & 41 & 41 & 46 & 39 \\
\hline bsYumC & & & 77 & 56 & 42 & 39 & 48 & 38 \\
\hline baFNR2 & U & 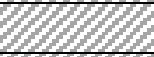 & & 54 & 41 & 41 & 46 & 41 \\
\hline ssFNR & & & & & 39 & 37 & 39 & 41 \\
\hline I/FNR & & & & & & 33 & 34 & 33 \\
\hline$b c$ FNR1 & & & & & & 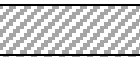 & 42 & 95 \\
\hline bsYcgT & & & & & & & 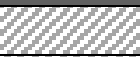 & 41 \\
\hline baFNR1 & & & & & 7 & & & \\
\hline
\end{tabular}




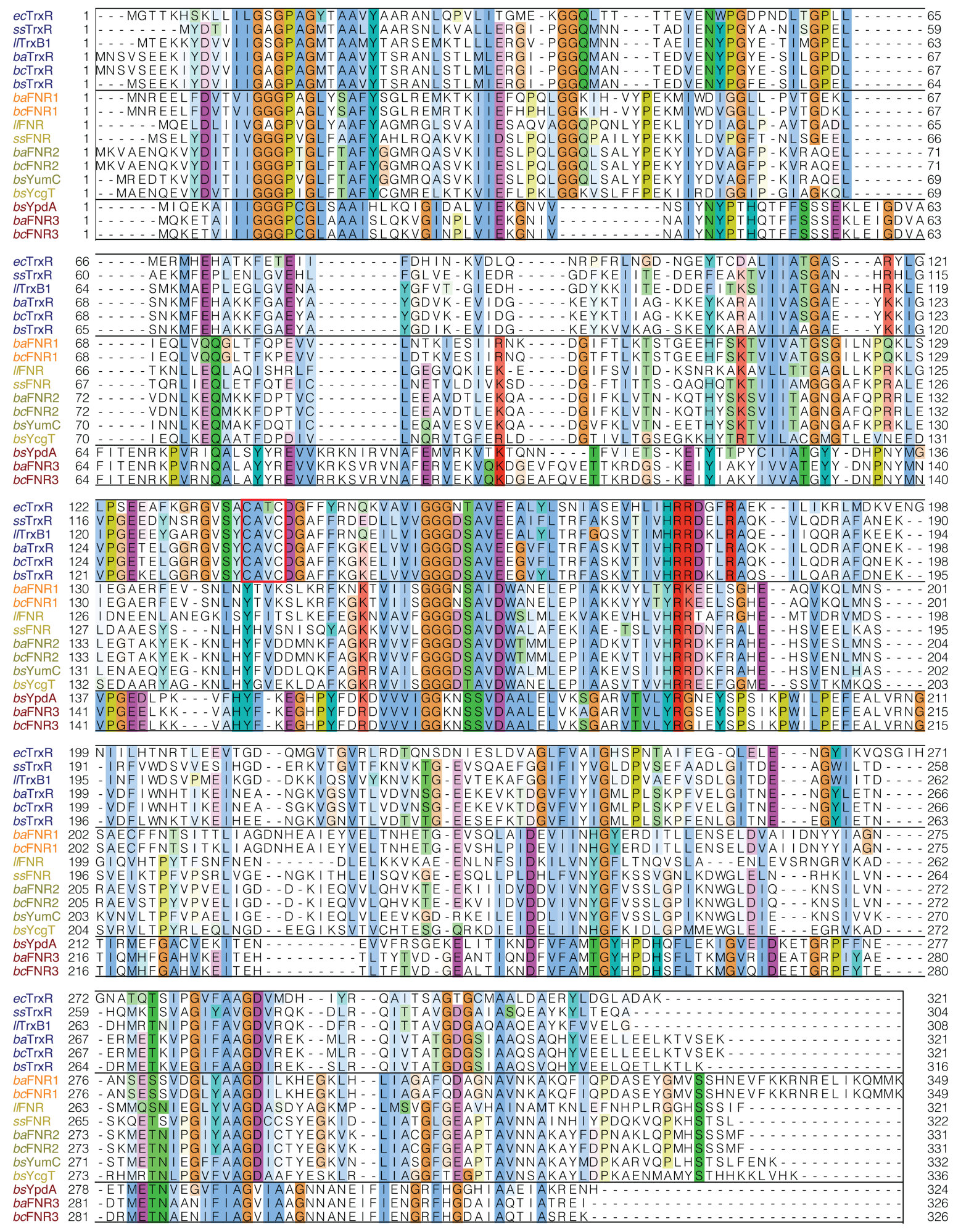

Figure S1. Multiple sequence alignment of TrxRs and FNRs in B. cereus (bc), B. anthracis (ba), B. subtilis (bs), L. lactis (ll), and S. sanguinis (ss), and the TrxR in E. coli (ec). The multiple sequence alignment was generated with Clustal Omega through Jalview. ${ }^{6,7}$ The coloring is according to Clustal X combined with color intensity adjusted to conservation by the AMAS method. ${ }^{15}$ The CXXC motif in TrxRs starts with amino acid 136 (E. coli numbering); see red box. The sequences are grouped according to the phylogenetic tree in Figure S2. 


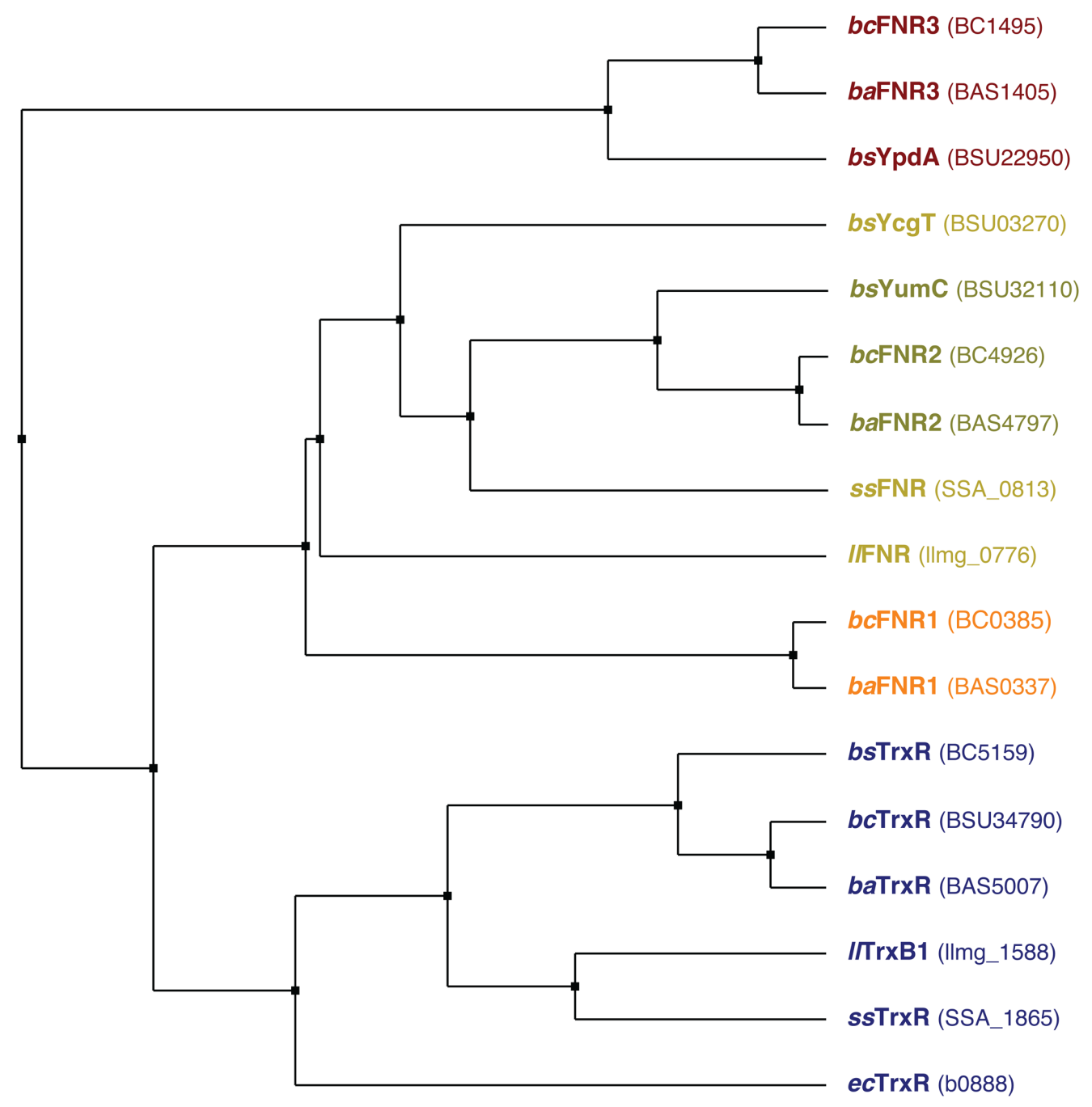

Figure S2. Phylogenetic tree of TrxRs and FNRs in B. cereus (bc), B. anthracis (ba), B. subtilis (bs), L. lactis (ll), and S. sanguinis (ss), and the TrxR in E. coli $(e c)$. The tree was calculated with Jalview and BLOSUM62 average distances based on the sequence alignment in Figure S1. ${ }^{7}$ The locus tags are listed in parentheses. 


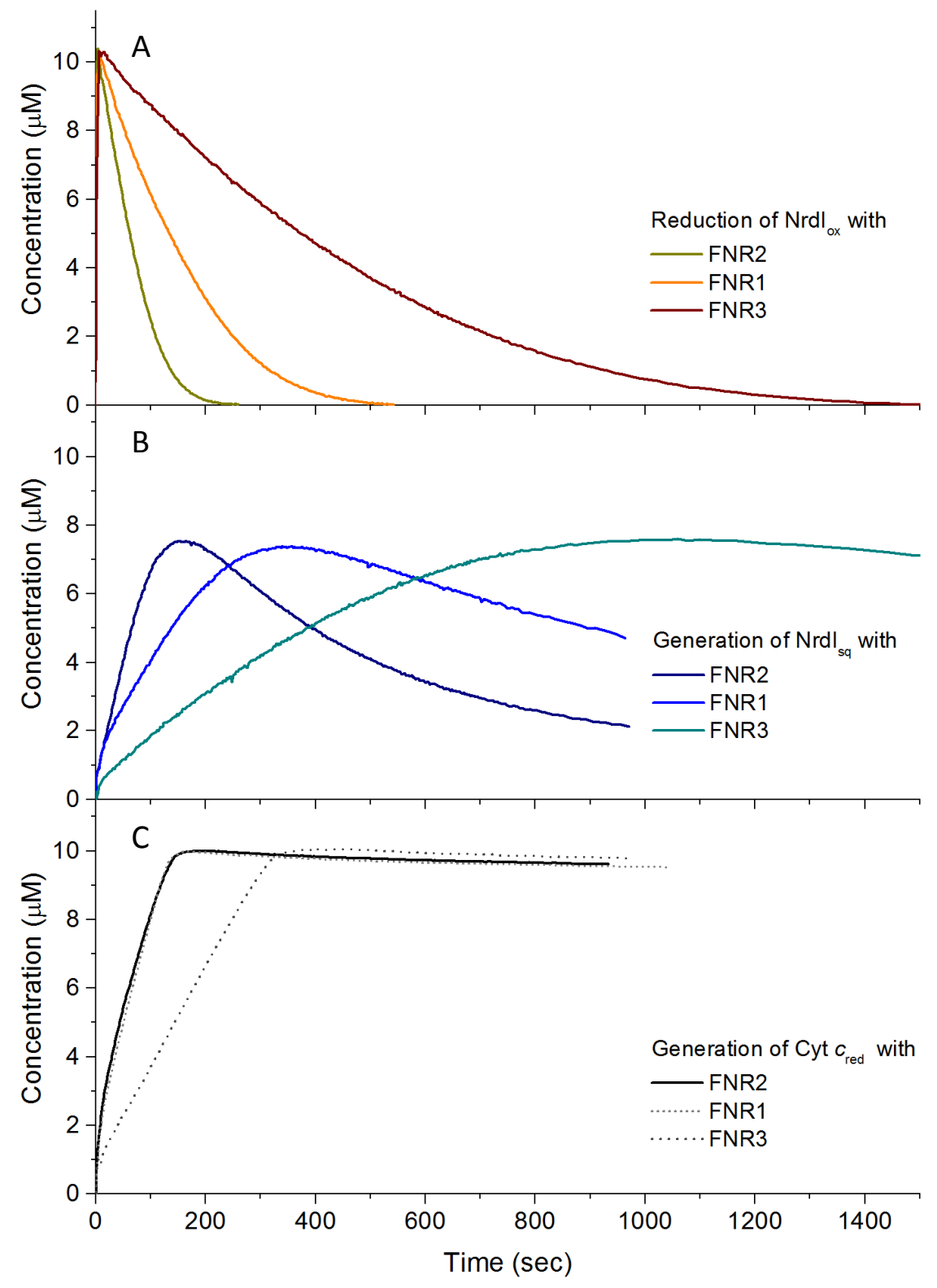

Figure S3. Reduction of $\mathrm{NrdI}_{\mathrm{ox}}(\mathrm{A})$, generation of $\mathrm{NrdI}_{\mathrm{sq}}$ (B), and generation of reduced cytochrome $c$ (Cyt $c_{\text {red }}$ ) (C) over time by the three FNRs, as monitored by UV-visible spectroscopy. The concentrations of $\mathrm{NrdI}_{\mathrm{ox}}, \mathrm{NrdI}_{\mathrm{sq}}$, and Cyt $c_{\text {red }}$ were determined from their absorbance at 447,575 , and $550 \mathrm{~nm}$, respectively, as described in detail in section S5. 


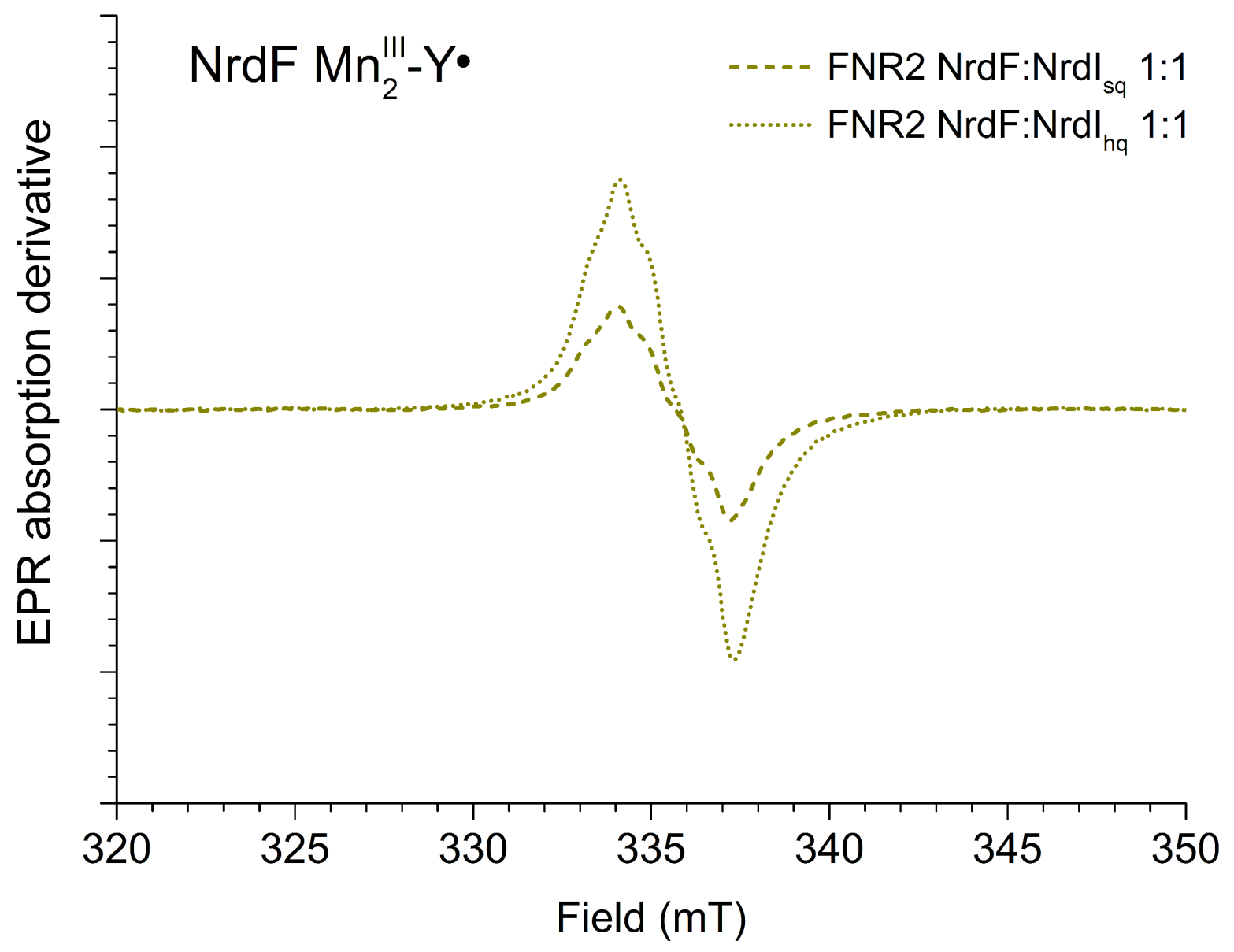

Figure S4. EPR spectra of activated NrdF protein collected at $77 \mathrm{~K}$. NrdF was activated with NrdI and FNR2 under pre-anaerobic conditions resulting in the following $\mathrm{Y} \bullet$ yield: $0.1 \mathrm{Y} \bullet / \beta_{2}\left(\operatorname{NrdI}_{\mathrm{sq}}\right), 0.2 \mathrm{Y} \bullet / \beta_{2}\left(\operatorname{NrdI}_{\mathrm{hq}}\right)$. Recording conditions: modulation amplitude, $0.2 \mathrm{mT}$; microwave power, $1 \mathrm{~mW}$. 


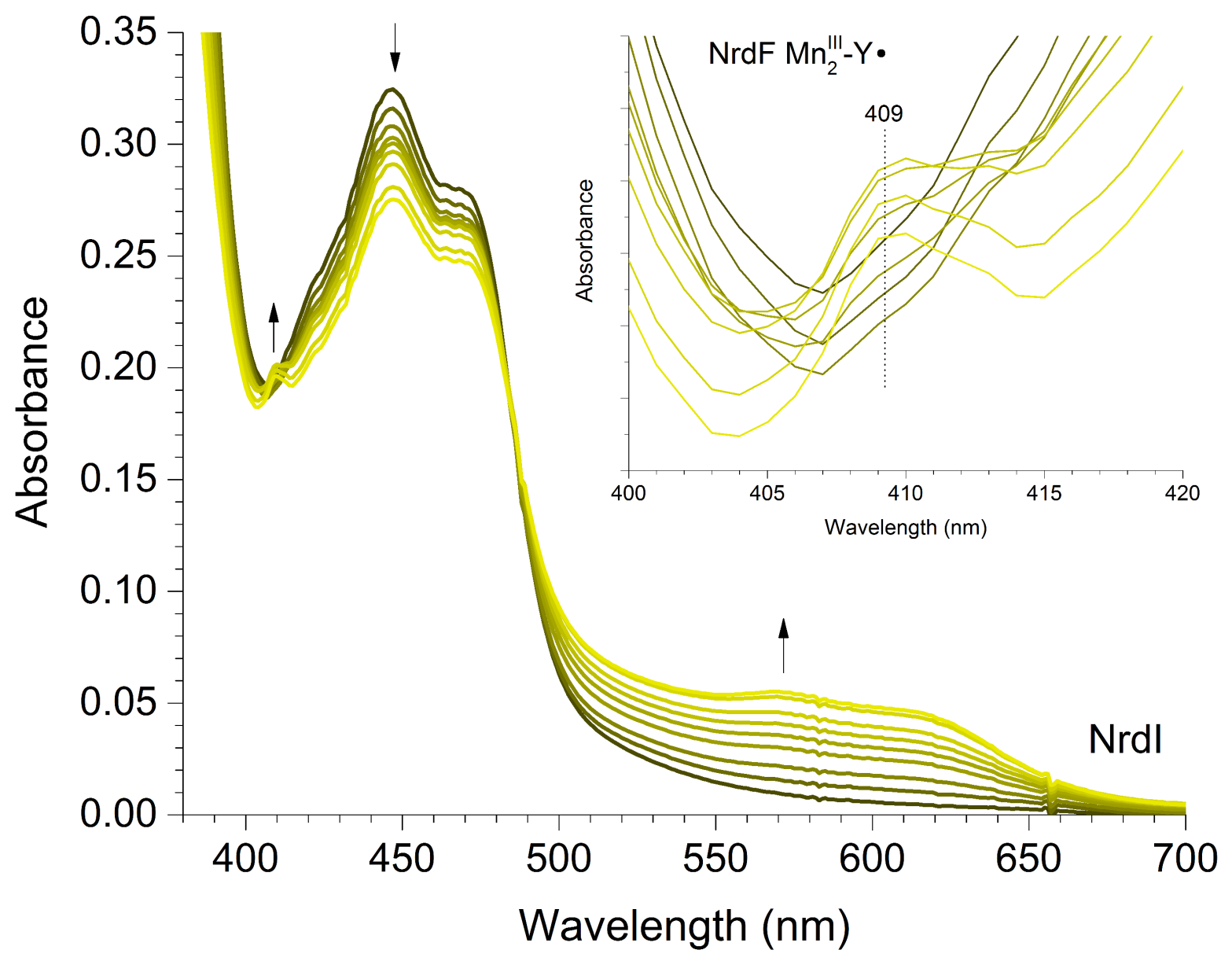

Figure S5. Aerobic activation of NrdF by NrdI and FNR2, as monitored by UV-vis spectroscopy. Inset: Build-up of the tyrosyl radical at $409 \mathrm{~nm}$ after mixing of $\mathrm{Mn}^{\mathrm{II}}-\mathrm{NrdF}$ (30 $\mu \mathrm{M}$ monomer), $\mathrm{NrdI}(30 \mu \mathrm{M})$, FNR $(3 \mu \mathrm{M})$ and $\mathrm{NADPH}(0.5 \mathrm{mM})$. 


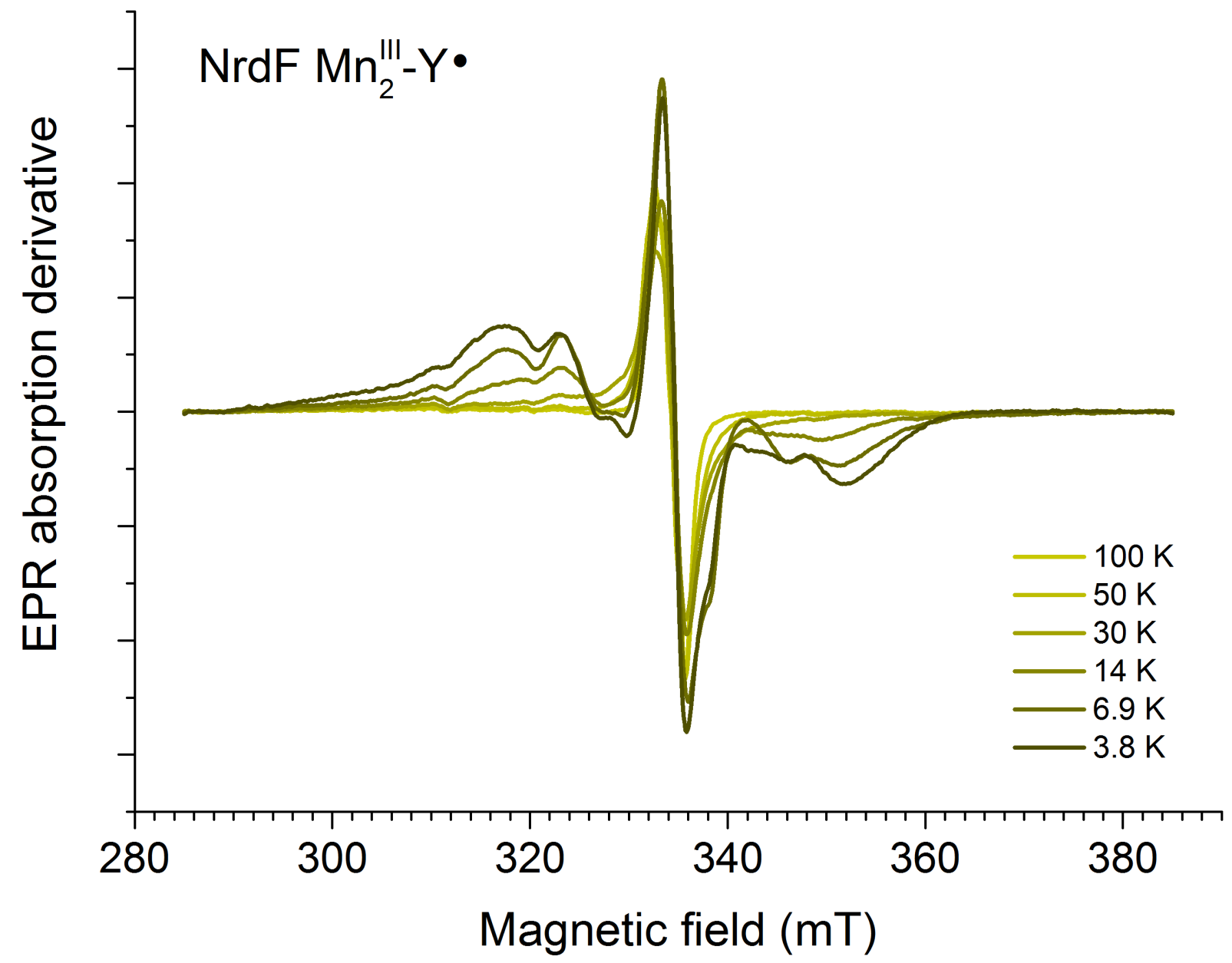

Figure S6. EPR-spectra of FNR2/NrdI activated $\mathrm{Mn}^{\mathrm{III}}{ }_{2}-\mathrm{Y} \bullet \mathrm{NrdF}$ obtained at different temperatures. $150 \mu \mathrm{M}$ NrdF monomer, $150 \mu \mathrm{M}$ NrdI, $15 \mu \mathrm{M}$ FNR2, $2.5 \mathrm{mM}$ NADPH. Recording conditions: modulation amplitude, $0.2 \mathrm{mT}$; microwave power, $1 \mathrm{~mW}$. 


\section{Section S8. References}

(1) Gustafsson, T. N., Sahlin, M., Lu, J., Sjöberg, B.-M., and Holmgren, A. (2012) Bacillus anthracis Thioredoxin Systems, Characterization and Role as Electron Donors for Ribonucleotide Reductase, J. Biol. Chem. 287, 39686-39697.

(2) Seo, D., Okabe, S., Yanase, M., Kataoka, K., and Sakurai, T. (2009) Studies of interaction of homo-dimeric ferredoxin-NAD $(\mathrm{P})+$ oxidoreductases of Bacillus subtilis and Rhodopseudomonas palustris, that are closely related to thioredoxin reductases in amino acid sequence, with ferredoxins and pyridine nucleotide coenzymes, Biochim. Biophys. Acta, Proteins Proteomics 1794, 594-601.

(3) Chen, J., Shen, J., Solem, C., and Jensen, P. R. (2015) A New Type of YumC-Like Ferredoxin (Flavodoxin) Reductase Is Involved in Ribonucleotide Reduction, mBio 6, e01132-15.

(4) Makhlynets, O., Boal, A. K., Rhodes, D. V., Kitten, T., Rosenzweig, A. C., and Stubbe, J. (2013) Streptococcus sanguinis Class Ib Ribonucleotide Reductase: High Activity with Both Iron and Manganese Cofactors and Structural Insights, J. Biol. Chem. 289, 6259-6272.

(5) Meyer, Y., Belin, C., Delorme-Hinoux, V., Reichheld, J. P., and Riondet, C. (2012) Thioredoxin and glutaredoxin systems in plants: molecular mechanisms, crosstalks, and functional significance, Antioxid. Redox Signal. 17, 1124-1160.

(6) Sievers, F., Wilm, A., Dineen, D., Gibson, T. J., Karplus, K., Li, W., Lopez, R., McWilliam, H., Remmert, M., Soding, J., Thompson, J. D., and Higgins, D. G. (2011) Fast, scalable generation of high-quality protein multiple sequence alignments using Clustal Omega, Mol. Syst. Biol. 7, 539.

(7) Waterhouse, A. M., Procter, J. B., Martin, D. M., Clamp, M., and Barton, G. J. (2009) Jalview Version 2--a multiple sequence alignment editor and analysis workbench, Bioinformatics 25, 1189-1191.

(8) Edebo, L. (1960) A new press for the disruption of micro-organisms and other cells, J. Biohem. Microbiol. Technol. Eng. 2, 453-479.

(9) Skråmo, S., Hersleth, H.-P., Hammerstad, M., Andersson, K. K., and Røhr, Å. K. (2014) Cloning, expression, purification, crystallization and preliminary $\mathrm{X}$-ray diffraction analysis of a ferredoxin/flavodoxinNADP (H) oxidoreductase (Bc0385) from Bacillus cereus, Acta Crystallogr., Sect. F: Struct. Biol. Commun. 70, 777780.

(10) Røhr, Å. K., Hersleth, H.-P., and Andersson, K. K. (2010) Tracking Flavin Conformations in Protein Crystal Structures with Raman Spectroscopy and QM/MM Calculations, Angew. Chem. Int. Ed. 49, 2324-2327.

(11) Tomter, A. B., Bell, C. B., 3rd, Røhr, Å. K., Andersson, K. K., and Solomon, E. I. (2008) Circular dichroism and magnetic circular dichroism studies of the biferrous site of the class Ib ribonucleotide reductase from Bacillus cereus: comparison to the class Ia enzymes, Biochemistry 47, 11300-11309.

(12) Berggren, G., Duraffourg, N., Sahlin, M., and Sjöberg, B.-M. (2014) Semiquinone-induced maturation of Bacillus anthracis ribonucleotide reductase by a superoxide intermediate, J. Biol. Chem. 289, 31940-31949.

(13) Gill, S. C., and von Hippel, P. H. (1989) Calculation of Protein Exctinction Coefficients from Amino Acid Sequence Data, Anal. Biochem. 182, 319-326.

(14) Aliverti, A., Curti, B., and Vanoni, M. A. (1999) Identifying and Quantitating FAD and FMN in Simple and in Iron-Sulfur-Containing Flavoproteins, In Flavoprotein Protocols (Chapman, S. K., and Reid, G. A., Eds.), pp 9-23, Humana Press, Totowa, NJ.

(15) Livingstone, C. D., and Barton, G. J. (1993) Protein sequence alignments: a strategy for the hierarchical analysis of residue conservation, Comput. Appl. Biosci. 9, 745-756. 